\title{
The Effectiveness of a Training Program Based on Frank Williams' Model in Developing the Divergent Creative Feeling among Students in Jordan
}

\author{
Fadi Soud Samawi \\ Department of Psychology and Special Education, \\ Princess Alia University College, Al-Balqa Applied University \\ Naifa Hamdan Hamad Alshoubaki \\ Department of Psychology and Special Education, \\ Princess Alia University College, Al-Balqa Applied University \\ Hassan Rafi' Ali Shaheen \\ Department of Psychology and Special Education, \\ Princess Alia University College, Al-Balqa Applied University
}

\begin{abstract}
The purpose of this study is to identify the effectiveness of using a training program based on Frank Williams' model of emotional cognitive interaction in the development of divergent creative feelings among tenth-grade students in King Abdullah II schools for excellence. A semi-experimental curriculum was used on a sample of (40) male and female students, the researchers distributed them randomly into two groups consisted of (20) students each, and they used the Creative Divergent Feeling Scale (LOLEMS), and they developed a program based on the emotional cognitive model. Results indicated the existence of the impact of the training program for the benefit of the experimental group, it also showed no differences due to the gender variable, and the results also showed that there are differences attributed to the parents' educational level variable in favor of the bachelor's degree holders. The study recommended the training of gifted students on the skills involved in the curriculum and the behavior of students in the emotional, cognitive interaction model, which helps them to develop a creative divergence feeling.
\end{abstract}

Keywords: Emotional; cognitive interaction model; divergent creative feeling; King Abdullah II Schools of Excellence

\section{Introduction}


Gifted people are considered a real asset for all societies in the world. So, educators face significant challenges related to their numbers and their upbringing to face the future and knowing their psychological, cognitive and social needs, represented in the cognitive component and original features of the original person, and to meet their needs adequately.

The development of thoughtful and creative mental capacities is the responsibility of all state institutions and on top of their priorities educational institutions, creative abilities exist for all individuals, still, they need development and training, indeed, the situation in schools refers to the typical instructional methods that hinder these capabilities and do not lead to the preparation of individuals capable of diversified and new production, that the overall development of our community's needs (Lowry, 2006).

The reality of what is going on in the classroom in schools confirms that education is limited only to certain content without accompanied by growth in thinking, therefore, the need for innovation in the educational system has become urgent through building curricula that improve the thinking of students, the outputs of these systems are of compelling specifications so that they possess the characteristics of higher and creative thinking (Jamal, Huwaidi, and Ben Dania, 2003).

(Jauk et al., 2015) in his study declared that the essence of creativity is divergent thinking (DT), which means that the individual can produce as many answers to the problem as possible. Therefore, tasks of DT were used for a long time to evaluate the creativity of individuals (Sayed and Mohamed, 2013), and the most popular psychometric assessment tools in the research fields of creativity were DT tests (Acar and Runco, 2014).

The emotional, cognitive interaction model which was developed by Frank Williams is a model based on several studies of the creative person and the creative process; it seeks to develop eight abilities in mental, physical, and emotional development. These abilities are General Intelligence, Academic Uses, Leadership, Creative Thinking, Visual and Performing Arts, Physical and Kinetic Development, Emotional development, self-concept, professional and functional practice that is, and the development of total human capacity. The model consists of three dimensions each one interacts with the other, it demonstrates how content (first dimension) can be prepared and organized through teaching methods and strategies in the classroom (second dimension), to produce diverse thought-provoking behaviors and saturated productive emotions (third dimension) (Talafha, 2009).

Frank Williams developed his model called emotional, cognitive interaction to interpret creative thinking as an interaction of four cognitive components: originality, flexibility, fluency, and detail with four sensitive elements: imagination, risk, complexity, and curiosity to produce creative output (Katami, 2010).

Creativity includes convergent thinking in addition to divergent thinking. What is meant by divergent thinking is to produce various answers or to think 
creatively as referred to by "think out of the box". Among the regular evaluations of divergent thinking is producing various ideas, as it is evaluated by other users of the task. On the other hand, convergent thinking means that when the individual has many answers, he can choose the most logical one. In fact, "evaluation of the novelty" which is a knowledge dependent, interacts with divergent thinking, and in situations where we have ready answers, it is very effective and what the individual need is only to recall his stored information (Ritter and Ferguson, 2017)

Through the CAI model, teachers can provide real opportunities for integrated and meaningful learning and a combination of knowledge acquisition and how to learn skills, students can be taught to focus on issues that need to be investigated and developed, and to develop problem-solving skills to include problem identification, research, and investigation, develop the necessary skills to organize, manage and implement problem-solving information, and ultimately learn to create and improve products that are qualitatively higher than students' age and grade levels (Newman, 2005).

Scholars defined Williams' model as a three-dimensional cube, a non-taxonomic structural model in which each dimension interacts with each other; each aspect contains a set of elements and branching sections, a model of practical development used by the teacher to develop cognitive and emotional processes in students (Al-Farra, 2007).

Frank Williams's model aims to enhance the cognitive and emotional processes necessary for creative production, feelings of poll, curiosity, risk, complexity, and imagination were developed by the traditional content of the topic, it resembles some extent the paradigm of the cultural structure of human intelligence developed by Gilford, which consists of three parts that interact with each other in any situation of the educational process, consequently, Frank Williams's creative divergent feeling Package reveals the students' inherent creative abilities (Al-Enezi, 2011), creativity, cognitive content, and skill should not be isolated variables, but it interact with each other, where creativity based on knowledge and expertise (Begheto \& plucker, 2006), consisting of the following dimensions (Khairallah, 2008):

1. Curiosity. It is the ability to search to discover the mystery, play with ideas, open to puzzling situations, and meditating on mysterious things, it is also essential to have an incentive to search for knowledge, to ask what things are and how they work, and to seek an in-depth understanding of the world around them.

2. Imagination. A person can build mental images, think of things that have not happened, and the use of sensual feeling to get meta-cognitive physical and realistic limits.

3. Complexity. It is the ability to challenge to recover alternatives and see the gap between reality and the imposed, and the ability to find systems and meaning of chaos and search for problems and challenging ideas.

In this model, Williams (1993a) interprets creativity as behavior resulting from eight components, and the cognitive part consists of the following skills: 
flexibility, fluency, originality and details, and the emotional domain consists of imagination, complexity, risk, and curiosity.

On the other hand, Harrison (1997) and Glynn (2007) claimed that there is a correlation between the organization of knowledge and emotions and the empowerment of the individual to be creative; the creative process is a specific cognitive mental process that forms the traits of thinking and creativity, it also enables the individual to organize his information, to build his perceptions, and thus to make emotional, mental transformations to reach divergent creative thinking.

Also, the emotional cognitive trend assumes that creativity is a cognitive process that is developed through training, and learning according to controlled conditions, and planned training situations in which the student uses cognitive mental skills (such as cognition, organization, comparison, spiritual transformations, analysis, synthesis, evaluation) to form, create something new, new experience, or creative solution, these skills require in-depth thinking that does not accept the processing of ideas, and information in a low level but it requires that the mind works to its fullest potential for the student to remain vigilant, attentive and sensitive to control these skills (Ghneim, 2005).

Gifted people are a human asset in any society, they are entitled to educational care consistent with their abilities and preparations, because they are high national energy and wealth that must be nurtured, to invest and direct this wealth to serve and develop the community, therefore, taking care of them is an indispensable cultural and educational necessity, especially in our Arab countries whose educational institutions lack the programs and strategies for gifted students. (Samadouni, 2014)

\subsection{Study problem and its questions}

Challenges that face our modern world need unconventional methods to cope with the growing developments in all fields that results from the development of information technology, to achieve the integrated development of the individual and taking care of him, by focusing on the learner's personality and preparing him for life, in addition to taking care of those talented and keeping school programs in line with the mental needs of the learners.

Gifted students also have cognitive and emotional needs and characteristics that distinguish them from other ordinary students which in turn affect their adaptation to the reality they live in, therefore, these students face problems and challenges, whether, at the level of personal life, or the level of family and school, this requires a more significant effort on the part of educational institutions to help them face these difficulties and challenges. The model of emotional cognitive interaction focuses on the cognitive and emotional aspects which are essential in the development of creative divergent feeling of students because it focused on the emotional side and feelings without which there is no meaning to creativity, which requires the development of special programs aimed at developing the capabilities of divergent creative sense and cares for 
creators early detection of them, in the light of the foregoing, the problem of the current research focused in answering the following questions:

1.1.1 The first hypothesis: There are statistically significant differences at the significance level $(\alpha=0.05)$ between the average performance of the experimental group and the average performance of the control group in developing the divergent creative feeling among gifted students in King Abdullah II schools of excellence in Salt City due to the training program.

1.1.2 The second hypothesis: There are statistically significant differences at the significance level $(a=0.05)$ between the average performance of the experimental group and the average performance of the control group in developing the creative divergent feeling among gifted students in the schools of King Abdullah II for excellence in the city of Salt due to the gender variable and educational level of the parents.

\subsection{The Purpose of the study}

The purpose of the current study is to reveal the effectiveness of the use of a training program based on Frank Williams' emotional, cognitive interaction model in the development of divergent creative feeling of tenth- grade students in King Abdullah II schools of excellence, the present study also seeks to clarify the concept of both the model of emotional cognitive interaction and divergent creative feeling, and to know whether the performance of both groups vary in the development of divergent creative feeling among gifted students in schools of King Abdullah II for excellence in the city of Salt due to the variables of gender and educational level of parents.

\subsection{The importance of the Study}

The significance of the study in its theoretical and practical aspects:

Theoretical significance: The significance of the research stems from the importance of the emotional, cognitive interaction model as a new instructional strategy in line with the local and global strategies, and to highlight the significance of Frank Williams' emotional, cognitive interaction model as a model with practical applications as a means of developing divergence creative feeling, so that the researchers, educators, teachers, counselors, and workers in the field of talent and creativity in all educational institutions benefit from it, and to identify and develop creative energies in all aspects of life, researching the various means to reveal the talented and creative people as the wealth of the nation in light of the race towards production and development, and that the teacher always needs to update his instructional information and skills, this study is a scientific addition to the Arab library in general, and the Jordanian library in particular.

Applied significance: to demonstrate the efficiency of using a training program based on Frank Williams' emotional, cognitive interaction model in developing divergence creative feeling among the students, and to draw the attention of educators in the educational technology departments to the importance and role 
of such models in achieving critical educational outcomes, it also seeks to reveal the exact role played by teachers and specialists in a way that gives an accurate picture highlighting the strengths and weaknesses in teaching, this study is a starting point for experimental studies in different educational institutions. The results of this study may benefit teachers, educational decision-makers and curriculum developers.

\subsection{Conventional and procedural definitions}

This study included several terms that were conceptually and procedurally defined as follows:

Cognitive Affective Interaction Model. A structural rather than a taxonomic model based on several studies on the creative person and the creative process, it aims to develop eight abilities looking at mental, emotional and physical development. These abilities are general intelligence, exceptional academic and leadership preparations, creative and complex thinking, physical and motor development, emotional development and self-concept, professional, functional, visual and performing arts, and these eight capacities contribute to the overall development of human potential (Williams, 1993a).

Divergent Creative Feeling. It is the emotional state of the creative individual, represented in four dimensions: Curiosity, imagination, complexity, and risk tolerance (Williams, 1993a), it is procedurally defined as the scores that the students get on the divergence creative feeling scale which was used in the study.

\subsection{The limits of the study and its limitations}

The limitations of the present study are as follows:

1. Human, Spatial, and Temporal limitations. Tenth Grade Students at King Abdullah II Schools of Excellence, Hashemite Kingdom of Jordan / Balqa Governorate, for the second semester of the academic year 2018/2019.

2. Objective limitations. It is the effectiveness of using a training program based on Frank Williams' emotional, cognitive interaction model in developing divergent creative feelings among tenth- grade students in King Abdullah II Schools of Excellence.

The results of the study are determined by the extent of psychometric characteristics of the emotional cognitive program, the scale of divergent creative feeling, the degree of cooperation of the study sample in the program, and their seriousness in answering the scale items.

\section{Literature Review}

Within the limits of their knowledge, the researchers did not find studies related to the variables of this study, but they found studies with individual variables, such as Vally, Salloum, Al Qedra, El Shazly, Albloshi, Alsheraif and Alkaabi 
(2019) a plethora of evidence suggests that creativity can be enhanced following training. In the United Arab Emirates, where creativity and innovation are overtly promoted, especially among young adults, university students complete a semester-long course in creativity as part of their undergraduate degrees. The effectiveness of this course, however, remains undetermined. Thus, they examined, using a sample of 133 participants who completed the 13-week program, whether improvements to creative production, creative self-efficacy (CSE), and neuro-executive functioning would emerge. Pre to post-test differences were assessed and substantial improvements to originality, elaboration, and fluency were observed. CSE was enhanced. However, neuroexecutive functioning remained unchanged following the program. These results contribute to the literature attesting to the efficacy of training in creative skills.

Fink, Reim, Benedek \& Garbner (2019) studied the effects of different types of creativity interventions on different facets of creative potential, also including more school-related creativity demands. In a sample of 77 fourth-graders in the age between 9 and 12 years, we administered verbal and figural creativity training, realized in two school lessons over two consecutive days each. As outcome measures, creative potential in both the verbal and the figural domain using two well-established divergent thinking tasks was assessed. As additional measures of creative potential, a story completion task and a picture painting task were administered to examine training effects on more school-related types of creative behavior. The verbal training was found to increase both verbal and figural divergent thinking ability, but not creative potential in the story completion and the picture painting task. The figural training yielded significant training effects only regarding the picture painting task.

Saleh's study (2016), which measured the impact of a training program in improving the communication skills of gifted students in King Abdullah II schools of excellence, this program based on the emotional cognitive interaction model. The study members consisted of all gifted female students in the ninth grade at King Abdullah II School of Excellence in Salt city, they were 40 talented students, chosen intentionally, and to achieve the study objectives, the researchers used a quasi-experimental approach, the results of the study showed that that the training program based on the emotional cognitive interaction model has an impact on improving the communication skills of gifted students, whether, on the total score, or sub-domains of communication skills of the experimental group, significant differences appeared in the scores of talented students in King Abdullah schools of excellence on the sub-domains of the communication skills scale due to the impact of the group in all domains.

Talafah and Alhamran (2013) investigated the effect of developing an educational unit according to the emotional, cognitive interaction model in teaching geography on perceived self-efficacy among a sample of tenth- grade students. The study sample was (112) $10^{\text {th }}$-grade students, distributed into four sections randomly selected from two government schools at Al Taibeh in the academic year 2010/2011, and the participants were randomly divided into two experimental and control groups. The results showed that the students of the experimental group (emotional, cognitive interaction model) were superior in 
the perceived self-efficacy scale as a whole, and in its five domains, the study found no statistically significant differences attributed to the gender variable.

Wang and Chen (2012) identified the impact of the emotional, cognitive interaction model on the creative performance of a sample of game designers. The study sample comprised of (198) $7^{\text {th }}$ - grade students who designed a group of games, and they were divided into two groups: experimental (45) students used foresight, transparency and interaction strategies, while the rest formed a control group. A pos/test was conducted to show that the strategy of the emotional, cognitive interaction model made it easier for students to design games creatively and enabled them to practice design flexibly and quickly.

Al-Enezi (2011) codified Frank Williams' creativity assessment packet in a sample of high school students in the State of Kuwait, the members of the study were (277) high school students, the researcher used the Frank William Scale (1993) to evaluate the creative feeling which included (50) items to measure the behavioral characteristics of the creators so that the scale consists of four dimensions: (Curiosity, imagination, complexity, risk tolerance), the study found that there is an effect of the class variable on the scale of feeling in favor of the eleventh grade, and no differences in the scale of feeling attributable to age variable.

Talafah (2009) investigated the impact of the Infinite Talent Program and the Emotional Cognitive Interaction Model in Teaching Geography on the creative abilities and perceived self-efficacy of a sample of tenth- grade students. The study sample comprised of (94) 10th- grade students distributed over three sections selected randomly from three public schools at Al- Mazar District in the academic year 2006/2007, where the researchers divided these three sections into control and experimental groups, and the results revealed differences between the averages of the first experimental group and the control group in favor of the first experimental group, which confirms the effectiveness of the infinite talent program, and the existence of differences between the mean of the second experimental group and the control group in favor of the second experimental group, which confirms the effectiveness of the emotional, cognitive interaction program in the development of creative thinking and its three elements (fluency, flexibility, and originality).

Karahan \& Yalcin (2009) investigated the effect of a training program based on emotional cognitive interaction on the development of emotional intelligence among a sample of students of the Turkish University, and whether these beneficial effects of the program persist over time, the participants of the study were (40) students who had low scores on the self-assessment of emotional intelligence and the researchers distributed them among two groups of (20) students, and the same number for the control, the results indicated that there were no significant differences on the pre-test between the two groups, but these differences appeared for the experimental group who underwent the training program on the posttest, the results also showed continued improvement in showing emotional intelligence skills in favor of the experimental group after the end of the program. 
Khairallah (2008) conducted a study on the legalization of Frank Williams CAP on (910) students from (3-6) primary grades to study the psychometric properties of the components of the package, the results of the study showed that feeling was characterized by high constructive validity, and the test phrases obtained high coefficients of excellence, and high scores on the reliability of internal consistency and split-half, and no differences in the degree of the responses of the members to the creative divergence scale depending on the interaction between gender and classroom variables.

Fraunberger (2004) conducted a qualitative study aimed at developing creative writing based on the theory between Williams's emotional, cognitive interaction model and Clark's model of distinctive characteristics of gifted students in America. The sample consisted of (50) talented students; he employed four of Williams' strategies: structured random research, intuitive expression, creative writing skills, visual representation skills, through the methods of qualitative analysis, he reached the effectiveness of these strategies in developing creative writing.

\section{The Study Methodology}

The quasi-experimental method in the equivalent group method (control group, experimental group, pre- and post-test) was used to determine the effectiveness of the use of a training program based on the model of emotional cognitive interaction of Frank Williams in the development of creative divergent feeling of tenth-grade students in King Abdullah II schools of excellence.

\subsection{Members of the study sample}

The study members consisted of all the tenth-grade gifted students in King Abdullah II School of Excellence in Salt City and their number (77) students for the second semester of the academic year 2018/2019, they were selected in an available way, for the school administration to cooperate with the researchers, and the divergent thinking scale was applied to the study members. After correcting the tool, it was found that there were (40) male and female students whose responses on the divergent thinking scale were below average.

The students were consulted about the program and all students agreed, they were divided into two groups equally in a simple random manner, the experimental group consisted of (20) students who received a training program based on Frank Williams' emotional, cognitive interaction model, and the control group consisted of (20) male and female students who did not receive the training program, the pre/ post scale measures were applied to both groups, according to Table (1): 
Table 1: Distribution of Study Members

\begin{tabular}{|c|c|c|c|c|c|c|c|}
\hline \multirow{2}{*}{$\begin{array}{c}\text { Study } \\
\text { variables }\end{array}$} & \multicolumn{2}{|c|}{ Gender } & \multicolumn{2}{c|}{ The educational level of parents } & \multirow{2}{*}{ Total } \\
\cline { 3 - 8 } & & & & Diploma & Bachelor & Postgraduate & \\
\hline & & Males & Females & & & & \\
\hline \multirow{2}{*}{ Group } & Experimental & 9 & 11 & 3 & 10 & 7 & 20 \\
\cline { 3 - 9 } & Control & 8 & 12 & 4 & 9 & 7 & 20 \\
\hline & Total & 17 & 23 & 7 & 19 & 14 & 40 \\
\hline
\end{tabular}

\subsection{The Scale of the Study}

\subsubsection{First: Creative Divergent Feeling Scale:}

To achieve the study's objectives, the Frank Williams scale was used to measure divergent emotional thinking, which was used in the study of Ghulam (2012), where the researcher applied the scale to a sample of (910) students between the ages of (9-12) years, the scale consists of 50 paragraphs that measure the following dimensions (curiosity, imagination, complexity, risk tolerance), for further verification, the validity of the test was confirmed by presenting it to a group of arbitrators from the faculty of education specialized in counseling and psychology, taking their views on the suitability of its domains and items, and the soundness of its language, and asked them to judge each paragraph of the test in terms of representation and adequacy for the category to which the study sample belongs, besides, in terms of language appropriateness. Based on the observations of the arbitrators, the wording of 4 items was amended and finalized. Also, indications of the validity of the internal consistency of the scale were extracted. The correlation coefficients of the paragraphs with the total score and the dimension were obtained in a pilot study consisting of (30) students.

Table 2: Correlation coefficients between items, total score and domain of creative divergence feeling scale

\begin{tabular}{|c|c|c|c|c|c|c|c|c|}
\hline $\begin{array}{c}\text { Item } \\
\mathrm{N}\end{array}$ & $\begin{array}{l}\text { Correlation } \\
\text { with } \\
\text { dimension }\end{array}$ & $\begin{array}{c}\text { Correlation } \\
\text { with tool }\end{array}$ & $\begin{array}{l}\text { Item } \\
\mathrm{N}\end{array}$ & $\begin{array}{l}\text { Correlation } \\
\text { with } \\
\text { dimension }\end{array}$ & $\begin{array}{c}\text { Correlation } \\
\text { with tool }\end{array}$ & $\begin{array}{l}\text { Item } \\
\mathrm{N}\end{array}$ & $\begin{array}{l}\text { Correlation } \\
\text { with } \\
\text { dimension }\end{array}$ & $\begin{array}{c}\text { Correlation } \\
\text { with tool }\end{array}$ \\
\hline 1 & $.413^{* *} 0$ & $.444^{*} 0$ & 18 & $.563^{* *} 0$ & . $370^{*} 0$ & 35 & $.386^{* *} 0$ & $.700^{\star *} 0$ \\
\hline 2 & $0.381^{* *}$ & $.828^{* *} 0$ & 19 & $.557^{\star *} 0$ & $.533^{* *} 0$ & 36 & $.535^{* *} 0$ & $.477 * 0$ \\
\hline 3 & $.592^{* *} 0$ & $.395^{\star} 0$ & 20 & $0.694^{* *}$ & $.456^{*} 0$ & 37 & $.507^{* *} 0$ & $.521^{* *} 0$ \\
\hline 4 & $.477^{* *} 0$ & $.581^{* *} 0$ & 21 & $.507^{* *} 0$ & $419^{*} 0$ & 38 & $.323^{* *} 0$ & $0.481^{*}$ \\
\hline 5 & $.435^{* *} 0$ & $0.395^{*}$ & 22 & $.547^{* *} 0$ & $.423^{*} 0$ & 39 & $.246^{* *} 0$ & $.549^{* *} 0$ \\
\hline 6 & $.572^{* *} 0$ & $0.493^{* *}$ & 23 & $.532^{* *} 0$ & $412^{*} 0$ & 40 & $.553^{*} 0$ & $.651^{* *} 0$ \\
\hline 7 & $.478^{\star *} 0$ & $0.541^{* *}$ & 24 & $.543^{\star *} 0$ & $.453^{*} 0$ & 41 & $.368^{\star *} 0$ & $.421^{*} 0$ \\
\hline 8 & $.359^{* *} 0$ & $0.692^{* *}$ & 25 & $.557^{* *} 0$ & $.608^{* *} 0$ & 42 & $.401^{*} 0$ & $.812^{* *} 0$ \\
\hline
\end{tabular}




\begin{tabular}{|c|r|r|r|r|r|r|r|r|}
\hline $\begin{array}{c}\text { Item } \\
\mathrm{N}\end{array}$ & $\begin{array}{c}\text { Correlation } \\
\text { with } \\
\text { dimension }\end{array}$ & $\begin{array}{c}\text { Correlation } \\
\text { with tool }\end{array}$ & $\begin{array}{c}\text { Item } \\
\mathrm{N}\end{array}$ & $\begin{array}{c}\text { Correlation } \\
\text { with } \\
\text { dimension }\end{array}$ & $\begin{array}{c}\text { Correlation } \\
\text { with tool }\end{array}$ & $\begin{array}{c}\text { Item } \\
\mathrm{N}\end{array}$ & $\begin{array}{c}\text { Correlation } \\
\text { with } \\
\text { dimension }\end{array}$ & $\begin{array}{c}\text { Correlation } \\
\text { with tool }\end{array}$ \\
\hline 9 & $.563^{* *} 0$ & $.370^{*} 0$ & 26 & $.386^{* *} 0$ & $.700^{* *} 0$ & 43 & $.413^{* *} 0$ & $.444^{*} 0$ \\
\hline 10 & $.557^{* *} 0$ & $.533^{* *} 0$ & 27 & $.535^{* *} 0$ & $.477^{*} 0$ & 44 & $0.381^{* *}$ & $.828^{* *} 0$ \\
\hline 11 & $0.694^{* *}$ & $.456^{*} 0$ & 28 & $.507^{* *} 0$ & $.521^{* *} 0$ & 45 & $.592^{* *} 0$ & $.395^{*} 0$ \\
\hline 12 & $.507^{* *} 0$ & $.419^{*} 0$ & 29 & $.323^{* *} 0$ & $0.481^{*}$ & 46 & $.477^{* *} 0$ & $.581^{* *} 0$ \\
\hline 13 & $.547^{* *} 0$ & $.423^{*} 0$ & 30 & $.246^{* *} 0$ & $.549^{* *} 0$ & 47 & $.435^{* *} 0$ & $0.395^{*}$ \\
\hline 14 & $.532^{* *} 0$ & $.412^{*} 0$ & 31 & $.553^{*} 0$ & $.651^{* *} 0$ & 48 & $.572^{* *} 0$ & $0.493^{* *}$ \\
\hline 15 & $.543^{* *} 0$ & $.453^{*} 0$ & 32 & $.368^{* *} 0$ & $.421^{*} 0$ & 49 & $.478^{* *} 0$ & $0.541^{* *}$ \\
\hline 16 & $.557^{* *} 0$ & $.608^{* *} 0$ & 33 & $.401^{*} 0$ & $.812^{* *} 0$ & 50 & $.359^{* *} 0$ & $0.692^{* *}$ \\
\hline 17 & $.386^{* *} 0$ & $.700^{* *} 0$ & 34 & $0.694^{* *}$ & $.456^{*} 0$ & & & \\
\hline
\end{tabular}

* Statistical significance at the level of significance (0.05). ** Statistical significance at the level of importance (0.01).

It is clear from Table (2) that the correlation coefficients of the items with the total degree and with the domain were statistically significant at significance levels $(\alpha=0.05)$ and $(0.01)$, therefore, none of them has been deleted, indicating that the scale domains are suitable for measuring divergent creative feeling, thus, indicating that the scale has a high level of validity and its relevance for the current study.

The reliability of the instrument was also verified in two ways. First, the AlphaCronbach method: The researchers calculated the coefficient of reliability AlphaCronbach for the domains of the scale and ranged between (0.74-0.78). The second split-half method: The reliability of the scale was calculated by the splithalf or division method of the four domains, ranging between $(0.68-0.71)$ on a pilot study of (30) students. Table 3 illustrates this:

Table 3: Alpha-Cronbach's reliability coefficients and Split-half reliability of the scale domains and the total divergent feeling scale

\begin{tabular}{|c|c|c|}
\hline Scale domains & Alpha Cronbach & split-half reliability \\
\hline Curiosity & 0.74 & 0.68 \\
\hline Imagination & 0.76 & 0.69 \\
\hline Complexity & 0.77 & 0.70 \\
\hline Risk tolerance & 0.78 & 0.71 \\
\hline Overall scale & $\mathbf{0 . 8 0}$ & $\mathbf{0 . 7 3}$ \\
\hline
\end{tabular}


The researchers also corrected the scale by placing in front of each item a fivestep ladder according to Likert's pentagonal method, where it shows the degree of applicability of the content of the paragraph to the subject, it is as follows: very large (5), large (4), medium (3), low (3), very low (1), thus, the total score of the scale between (24-120), the higher the degree indicates a high level in the divergence creative feeling and vice versa.

\subsubsection{Second: The Training Program}

First: Definition of the Program

The researchers reviewed the educational literature and related previous studies, accordingly, a training program was built based on the emotional, cognitive interaction model in developing the divergent creative feeling among the tenthgrade gifted students, which includes training activities and skills that employ the four skills: "curiosity, imagination, complexity, and risk tolerance", where the curriculum consists of all subjects from primary to tenth- grade and consists of four courses: (Language, mathematics, science, social, science) where it consists of (8) strategies that teachers can use them during their presentation of content as a way of demonstrating four cross-sectional behaviors that can be applied to develop creativity in any of the previous content topics, the most important of which are: creative writing and creative reading, contradictions, characteristics, symmetries, inequalities, provocative questions, examples of change, tolerance of ambiguity, inclinations, and desires of creative people.

Second: The objectives of the training program:

*The overall aim of the program is to develop a divergent creative feeling of gifted students through training on the emotional, cognitive interaction model strategies of Frank Williams.

\section{Special Program Objectives}

1. To introduce the gifted tenth- grade students to the concept of divergent creative feeling.

2. To train talented $10^{\text {th }}$ - grade students on how to develop a creative divergent feeling.

3. To enrich and refine the abilities and skills of the trainees to develop the skills of divergent creative feeling.

4. To employ and use emotional, cognitive interaction model strategies to become a key input in the education process.

Third: Target group: Tenth- grade gifted students at King Abdullah II School of Excellence in Salt. 
Fourth: Program Design:

1. Review several training programs used in the theoretical literature and previous studies that are related to the model of emotional, cognitive interaction and divergent creative feeling.

2. Define the general framework of the training program within the emotional, cognitive interaction model, and analyze the four areas: "curiosity, imagination, complexity, risk tolerance".

3. Define all the domains of divergence creative feeling that the researchers will train the students on it, and they collect a large number of activities and training for the development of each domain, and some activities were selected and modified, and they design new activities that suit the age, target group, and educational environment.

4. Coordinate activities in the form of training sessions within a specified period, including several objectives, actions, and strategies.

Fifth: The validity of the training program: After the completion of the training program, the researchers presented to a group of arbitrators working in Jordanian universities and workers in educational psychology, special education, psychological counseling, measurement and evaluation to ensure the appropriateness of the program activities for the target group, and the effectiveness of the training program in achieving the objectives set, and the extent to which the items are linguistically accurate, and the clarity of the content, objectives, activities and procedures and their relevance to the target group.

After the arbitration procedure, the researchers did the appropriate modifications to the training program in the light of the opinions of the arbitrators and they finalized in preparation for applying it to the study members, a criterion (80\%) was adopted to change, add or delete some activities, so that the duration of the session was adjusted from (45) minutes to (60) minutes.

Sixth: The content of the training program: The training program consisted of ten training sessions including objectives, procedures, and activities for the areas included in the four capacities in the emotional, cognitive interaction model, it was implemented at the King Abdullah II School of Excellence in Salt city, the duration of implementation of the program was approximately four weeks (one month) to train gifted students to develop a divergence creative feeling through the model of emotional cognitive interaction, it consisted of (10) training sessions at the rate of two sessions per week, and each session lasts for (60) minutes. 
Seventh: The Operational Plan of the Training Program:

\begin{tabular}{|c|c|c|c|}
\hline Session & Training skill & Objectives of the session & $\begin{array}{c}\text { Session } \\
\text { duration }\end{array}$ \\
\hline First session & $\begin{array}{ll}\text { Introduction } & \text { and } \\
\text { definition } & \end{array}$ & $\begin{array}{l}\text { Gifted students are introduced } \\
\text { to the goals of the program, to } \\
\text { the role assigned to it during the } \\
\text { training program, and to the } \\
\text { strategies of the emotional, } \\
\text { cognitive interaction model. }\end{array}$ & 60 minutes \\
\hline $\begin{array}{l}\text { Second } \\
\text { session }\end{array}$ & $\begin{array}{l}\text { The idea of divergent } \\
\text { creative feeling, its } \\
\text { importance, and its } \\
\text { elements }\end{array}$ & $\begin{array}{l}\text { Gifted students are introduced } \\
\text { to the idea of divergent creative } \\
\text { feeling and the importance of } \\
\text { creativity in everyday life }\end{array}$ & \\
\hline $\begin{array}{l}\text { Third } \\
\text { session }\end{array}$ & $\begin{array}{ll}\text { Vision } & \text { and } \\
\text { visualization } & \end{array}$ & $\begin{array}{l}\text { Developing the ability to } \\
\text { visualize and imagination, the } \\
\text { ability to build mental fantasies, } \\
\text { the formation of integrated } \\
\text { mental images of the imagined } \\
\text { thing, the development of } \\
\text { pictures if invention to } \\
\text { accomplish and achieve }\end{array}$ & 60 minutes \\
\hline $\begin{array}{l}\text { Fourth } \\
\text { session }\end{array}$ & Listening & $\begin{array}{l}\text { Introduce students to listening } \\
\text { skills, train them and strengthen } \\
\text { social relationships through } \\
\text { good listening }\end{array}$ & 60 minutes \\
\hline $\begin{array}{l}\text { Fifth } \\
\text { session }\end{array}$ & Speaking & $\begin{array}{l}\text { Introduce students to speaking } \\
\text { skills, and train them in it }\end{array}$ & 60 minutes \\
\hline $\begin{array}{l}\text { Sixth } \\
\text { session }\end{array}$ & Complexity & $\begin{array}{l}\text { Students are introduced to the } \\
\text { skill of complexity, and the } \\
\text { ability to search for several } \\
\text { alternatives to solve a particular } \\
\text { problem }\end{array}$ & 60 minutes \\
\hline $\begin{array}{l}\text { Seventh } \\
\text { session }\end{array}$ & Curiosity & $\begin{array}{l}\text { Introduce students to curiosity, } \\
\text { train them to insist on things, } \\
\text { and follow what happens next }\end{array}$ & 60 minutes \\
\hline $\begin{array}{l}\text { Eighth } \\
\text { session }\end{array}$ & Risk tolerance & $\begin{array}{l}\text { Introduce students to the skill of } \\
\text { risk tolerance, practice, and } \\
\text { experiment with difficult } \\
\text { situations. }\end{array}$ & 60 minutes \\
\hline $\begin{array}{l}\text { Ninth } \\
\text { session }\end{array}$ & Feedback & $\begin{array}{l}\text { Explain feedback and train } \\
\text { students on feedback. }\end{array}$ & 60 minutes \\
\hline $\begin{array}{l}\text { Tenth } \\
\text { session }\end{array}$ & Evaluation Session & $\begin{array}{l}\text { Identify the advantages and } \\
\text { disadvantages of the training } \\
\text { program, and learn about the } \\
\text { educational benefit of the } \\
\text { training program }\end{array}$ & 60 minutes \\
\hline
\end{tabular}


Eighth: study design and statistical treatment:

This study uses quasi-experimental design, to determine the effect of the training program based on the emotional, cognitive interaction model in developing the divergent creative feeling of the experimental group, where the pre-application of the scale was to all the study members (experimental and control groups), and then the researchers apply the training program which was based on the Frank Williams emotional, cognitive interaction model in the development of divergent creative feeling to the experimental group only and not to the control group, after the completion of the training program, the posttest was applied to all the study members again from the experimental and control groups, the pre, post, and adjusted arithmetic averages and standard deviations were extracted taking into account the pre- differences between the two groups, and (ANCOVA) test was used to judge the significance of the differences between the mean scores of gifted students between the experimental and control groups, also, (MANCOVA) was extracted to extract significance differences in the sub-skills of the creative divergence scale between both groups.

The design of the present study is as follows:

- $\quad$ The experimental group (pretest - application of training program - post-test) (OXO).

- The control group (pre-test - non-application of the training program) (O O).

* Where $(\mathrm{O})$ represents the pre and post creative divergent feeling, and $(\mathrm{X})$ training program.

\section{The Study Results and its Discussion}

\begin{tabular}{|l|l|}
\hline The first hypothesis & $\begin{array}{l}\text { There are statistically significant differences between the } \\
\text { average performance of the experimental and control } \\
\text { groups in developing the divergent creative feeling } \\
\text { among gifted students due to the training program. }\end{array}$ \\
\hline The second hypothesis & $\begin{array}{l}\text { There are statistically significant differences between the } \\
\text { average performance of the experimental and control } \\
\text { groups in developing the creative divergent feeling } \\
\text { among gifted students due to the gender variable and } \\
\text { educational level of the parents. }\end{array}$ \\
\hline
\end{tabular}

The first hypothesis: There are no statistically significant differences at the significance level (=a0.05) between the average performance of the experimental group and the average performance of the control group in developing the divergent creative feeling among gifted students in the schools of King Abdullah II for excellence in the city of Salt due to the training program?

To investigate this question, the mean and standard deviations of the pre and post measurements and the adjusted arithmetic averages were extracted for the grades of gifted students in the King Abdullah schools for Excellence on the scale as a whole and on the sub-domains of the Creative Divergence Scale (for 
the two experimental groups) that underwent the training program (and control), that have not experienced the training program, the results are as follows:

Table 4: means and the standard deviations of the pre/post scores of the gifted students on the overall scale of the divergent creative feeling of the experimental and control groups

\begin{tabular}{|c|c|c|c|c|c|c|}
\hline \multirow{2}{*}{ Group } & \multicolumn{3}{|c|}{ Pre divergent creative feeling } & \multicolumn{3}{c|}{ Post divergent creative feeling } \\
\cline { 2 - 7 } & $\mathrm{N}$ & Mean & $\begin{array}{c}\text { Standard } \\
\text { deviation }\end{array}$ & $\mathrm{N}$ & Mean & $\begin{array}{c}\text { Standard } \\
\text { deviation }\end{array}$ \\
\hline Experimental & 20 & 163.14 & 15.85 & 20 & 184.27 & 12.79 \\
\hline Control & 20 & 171.49 & 17.36 & 20 & 162.97 & 19.67 \\
\hline Total & 40 & 167.49 & 16.61 & 40 & 173.62 & 16.23 \\
\hline
\end{tabular}

Table 4 shows the existence of apparent differences between the pre and post arithmetic averages of the communication skills of gifted students of the experimental and control groups, to illustrate the significance of the statistical differences between the arithmetic averages of the scale as a whole, ANCOVA was used and the results are presented below:

Table 5: Modified arithmetic averages and standard errors of students' scores on the creative divergent feeling scale in the experimental and control groups

\begin{tabular}{|c|c|c|}
\hline Group & Mean & Standard error \\
\hline Experimental & 188.74 & 3.01 \\
\hline Control & 161.49 & 3.38 \\
\hline Total & 175.12 & 2.19 \\
\hline
\end{tabular}

Table 6: Results of the ANCOVA analysis of the effect of the group on the overall scale of the divergent creative feeling of gifted students

\begin{tabular}{|c|c|c|c|c|c|}
\hline Source of variance & $\begin{array}{c}\text { Sum of } \\
\text { squares }\end{array}$ & Df & $\begin{array}{c}\text { Mean if } \\
\text { squares }\end{array}$ & F value & Sig \\
\hline $\begin{array}{c}\text { Pre/test } \\
\text { (accompanying) }\end{array}$ & 3249.76 & 1 & 3249.76 & 14.97 & ${ }^{*} 0.000$ \\
\hline Group & 7986.46 & 1 & 7986.46 & 35.69 & ${ }^{*} 0.000$ \\
\hline Error & 8724.67 & 42 & 187.45 & & \\
\hline Modified overall total & 17460.89 & 44 & & & \\
\hline
\end{tabular}

* Statistically significant at the significance level $(a=0.05)$ 
Table (6) revealed significant differences in the divergent creative feeling scale of gifted students due to the group variable with a value of $F$ (35.69), these differences were in favor of the experimental group, which had an adjusted mean of (188.74). The program has contributed to the development of the sense of divergent creative feeling of gifted students. The means and standard deviations of the dimensions of the creative divergent feeling scale were also extracted, as shown in Table 7:

Table 7: The means and standard deviations of the pre/post scores of the gifted students on the dimensions of the divergent creative feeling of the experimental and control groups

\begin{tabular}{|c|c|c|c|c|c|c|c|}
\hline \multirow{2}{*}{ Test } & \multirow{2}{*}{ Dimensions } & \multicolumn{2}{|c|}{ Experimental } & \multicolumn{2}{|c|}{ Control } & \multicolumn{2}{|c|}{ Total } \\
\cline { 2 - 8 } & & Mean & STD & Mean & STD & Mean & STD \\
\hline \multirow{4}{*}{ Pre/test } & Curiosity & 23.47 & 3.24 & 23.68 & 3.41 & 23.58 & 3.33 \\
\cline { 2 - 8 } & Imagination & 31.04 & 3.75 & 32.89 & 4.38 & 31.97 & 4.07 \\
\cline { 2 - 8 } & Complexity & 21.79 & 3.17 & 22.48 & 3.82 & 22.14 & 3.50 \\
\cline { 2 - 8 } & Risk tolerance & 33.46 & 4.19 & 35.19 & 4.73 & 34.33 & 4.46 \\
\hline \multirow{3}{*}{ Post/test } & Curiosity & 26.37 & 2.46 & 24.92 & 3.57 & 25.65 & 3.02 \\
\cline { 2 - 9 } & Imagination & 45.72 & 3.27 & 30.64 & 4.23 & 38.18 & 3.75 \\
\cline { 2 - 9 } & Complexity & 29.63 & 2.86 & 21.78 & 2.75 & 25.41 & 2.81 \\
\cline { 2 - 8 } & Risk tolerance & 46.83 & 3.98 & 33.63 & 4.87 & 4.23 & 4.43 \\
\hline
\end{tabular}

Table (7) shows the existence of apparent differences between the pre and post arithmetic averages of both groups in the sub-fields of the creative divergent feeling scale of gifted students; these results are presented below:

Table 8: Modified Computational Modifiers and Standard Errors for Students on Dimensions of the creative divergent feeling scale in the experimental and control groups

\begin{tabular}{|c|c|c|c|}
\hline Dimensions & Group & Mean & Standard error \\
\hline \multirow{2}{*}{ Curiosity } & Experimental & 26.79 & 0.49 \\
\cline { 2 - 4 } & Control & 22.74 & 0.74 \\
\hline \multirow{2}{*}{ Imagination } & Experimental & 34.02 & 0.41 \\
\cline { 2 - 4 } & Control & 32.08 & 0.75 \\
\hline \multirow{2}{*}{ Complexity } & Experimental & 26.21 & 0.51 \\
\cline { 2 - 4 } & Control & 22.94 & 0.54 \\
\hline \multirow{2}{*}{ Risk tolerance } & Experimental & 39.07 & 0.89 \\
\cline { 2 - 4 } & Control & 33.38 & 0.79 \\
\hline
\end{tabular}

Table (8) revealed significant differences in the creative divergent feeling scale of gifted students due to the group variable in favor of the experimental group, this is attributed to the activities and exercises involved in the program based on 
Emotional Cognitive Interaction model, the training program enabled students to interact with each other within a framework of respect and responsibility, this helped them to express themselves, increasing their motivation for further exploration, the practice of imagination, students also can interact with its contents and thus had the motivation to continue learning, and that they can learn, and that through the use of different strategies provided the students with the technical expertise necessary for the process of learning, this is confirmed by Newman (2005) that the model of cognitive interaction offers real opportunities for an integrated and meaningful education and its synthesis that includes acquiring knowledge and learning skills while ensuring that students can focus on issues that need to be investigated and develop problem-solving skills to identify the problem and the areas of research and inquiry, and to develop the necessary skills to organize, manage and implement information that investigates the issue.

This finding agreed with the results of the Talafah and Hamran (2013) study, which demonstrated the superiority of the experimental group (the cognitiveemotional interaction model) in the perceived self-efficacy scale as a whole, and its five domains, the result was also agreed with the result of Wang and Chen (2012) study, which showed that the strategies of the cognitive interaction model made it easier for students to design games creatively and help them to practice flexibly and quickly. Vally, Salloum, Al Qedra, El Shazly, Albloshi, Alsheraif and Alkaabi (2019) concluded that the training program increased students' creativity. The result goes with Fink, Reim, Benedek \& Garbner's (2019) study which concluded that. The verbal training was found to increase both verbal and figural divergent thinking ability, but not creative potential in the story completion and the picture painting task.

The second hypothesis: There are no statistically significant differences at the mean level $(\alpha=0.05)$ between the average performance of the experimental group and the average performance of the control group in the development of the creative divergent feeling of the gifted students in the King Abdullah II School of Excellence in Salt city due to gender variable and educational level for parents. Means and standard deviations of the study sample were calculated according to the variables of gender and the educational level of the parents. Table 9 illustrates this.

Table 9: Means and standard deviations of the study sample according to gender variables and educational level of parents

\begin{tabular}{|l|c|c|c|c|}
\hline \multicolumn{2}{|c|}{ Variables } & Mean & $\begin{array}{c}\text { Standard } \\
\text { deviation }\end{array}$ & Rank \\
\hline \multirow{3}{*}{ Gender } & Females & 3.19 & 0.79 & 1 \\
\cline { 2 - 5 } & Males & 3.21 & 0.85 & 2 \\
\hline \multirow{2}{*}{$\begin{array}{l}\text { Educational level of } \\
\text { parents }\end{array}$} & Diploma & 2.74 & 0.86 & 3 \\
\cline { 2 - 5 } & Bachelor & 3.41 & 0.72 & 1 \\
\cline { 2 - 5 } & Postgraduate & 2.92 & 0.85 & 2 \\
\hline
\end{tabular}


As noted from Table 9, there are differences in gender, where the female group constituted the highest percentage of the study sample with a mean of (3.19), while the mean of the male category reached (3.21), there are also slight differences concerning the educational level of the parents, where students whose parents' educational level is bachelor's degree obtained the highest mean of (3.41), followed by students whose parents' educational level is postgraduate with a mean of (2.92), and students whose parents' educational level diploma with a mean of (2.74).

To verify the differences between the arithmetic averages in the study sample according to the gender variable and the educational level of the parents, TwoWay analysis of variance between the means for each was performed, as shown in Table 10 below:

Table 10: Two-Way analysis of variation of the study sample according to the study variables

\begin{tabular}{|c|c|c|c|c|c|}
\hline Source & $\begin{array}{c}\text { The level of } \\
\text { divergent feeling }\end{array}$ & $\begin{array}{c}\text { Sum of } \\
\text { squares }\end{array}$ & $\begin{array}{c}\text { Mean of } \\
\text { squares }\end{array}$ & (F) value & Sig \\
\hline Gender & Divergent feeling & .347 & .519 & 1.239 & .116 \\
\hline $\begin{array}{c}\text { The educational } \\
\text { level of parents }\end{array}$ & Divergent feeling & .2176 & .2541 & .6344 & $.009^{*}$ \\
\hline Error & Divergent feeling & 38.239 & .254 & & \\
\hline Total & Divergent feeling & 38.658 & & & \\
\hline
\end{tabular}

* Statistically significant at the level of $(a=0.05)$

Where the calculated value of $(F)$ was 1.239, the significance level (0.116) which is higher than the statistical significance level (0.05), this is attributed to the educational level of the parents and for the benefit of the bachelor's degree holders, the value of calculated (F) was (4.634) and the significance level (0.009) which is lower than the statistical significance level (0.05).

Results showed that the model was able to develop the divergent creative feeling among male and female students alike, this is due to the nature of the balanced activities included in the program, which unleashed the creative potential of male and female students, helping them to express themselves freely, and to solve problems, and to raise their learning level. This may be because teaching of both sexes was done at the same level and within the same activities and procedures, and thus the development of their divergent creative abilities was similar in the context of parental educational level variable, this can be attributed to the nature of individual differences between students themselves, the quality of parents' education and follow-up to their children. Therefore creative energies differ from student to student. In this context, AlEnezi (2019) noted that Frank Williams' divergent creative model is used to reveal the creative potential of all students in the school, and creativity, cognitive content, and skill should not be isolated variables, but interact with each other so that creativity depends on knowledge and expertise. 


\section{Recommendations}

1. To include extra-curricular activities that might develop creativity and ability to think in creative ways in schools.

2. To train talented students on the skills involved in the curriculum and the behavior of students in the emotional, cognitive interaction model, and this helps them to develop a creative divergence feeling.

3. To develop different curricula in terms of content and objectives, and their activities so that they are more appropriate to create the creative feeling of students at different educational levels.

4. To conduct further studies dealing with the application of emotional, cognitive interaction model strategies to gifted students at different ages and comparing them with ordinary students.

\section{References}

Acar, S., \& Runco M. (2014). Assessing associative distance among ideas elicited by tests of divergent thinking. Creative Research Journal, 26(1), 229-238. https://doi.org/10.1080/10400419.2014.901095

Al-Enezi, F. (2001). Psychology of innovation and underdevelopment. Kuwait: Al - Falah Library for Publishing and Distribution.

Al-Enezi, F. (2011). Rationing the Feeling Scale for Creativity by Frank Williams in a Sample of High School Students in the State of Kuwait. Journal of Childhood and Education, 3(7), 13-53.

Al-Farra, R. (2007). The impact of storytelling on the development of creativity among a sample of fourth- grade children (Unpublished doctoral dissertation). University of Jordan, Jordan.

Al-Samadouni, A. (2014). Education of the Gifted and Distinguished. Dar Al-Fikr for Publishing and Distribution, Amman, Jordan.

Beghetto, R., \& Plucker, J. (2006). The relationship among schooling ‘ learning ، and creativity: "All roads lead to creativity" or "You can't get there from here?" In J. C. Kaufman \& J. Bear (Eds.). Creativity and Reason in Cognitive Development (316-332). Cambridge، NY: Cambridge University Press. https://doi.org/10.1017/cbo9780511606915.019

Fink, A., Reim, T., Benedek, M., \& Garbner, R. (2019). The Effects of a Verbal and a Figural Creativity Training on Different Facets of Creative Potential. Journal of Creative Behavior, 1(1), 1-10. https://doi.org/10.1002/jocb.402

Fraunberger, J. (2004). Affective Characteristics in The Creative Classroom. The University of Illinois. Retrieved from www.fraunberger.com

Ghoneim, M. (2005). Basic concepts in cognitive psychology. Alexandria: Alexandria Book Center.

Ghulam, H. (2008). Standardization of Frank Williams' Innovation Assessment Package (CAP) for Grade 3 to 6 Primary Students in the Kingdom of Bahrain (Unpublished Master Thesis). Arabian Gulf University, Bahrain.

Glynn, S. (2007) The Teaching with Analogies model: Build Conceptual bridge with Mental Models. (Methods Strategies: Ideas and Technologies to enhance your Science Teaching. Washington, DC: National Science Teacher Association. 
Harrison, A. (1997). Conceptual Change in Secondary Chemistry: The Role of Multiple Analogical Models of Atoms And Molecules (Unpublished Ph.D. Dissertation). Curtin University of Technology, Perth, Western Australia.

Jamal, M., Huwaidi, Z., \& Ben Daniah, A. (2003). Methods of detection of creative and talented and the development of thinking and creativity. Al Ain, the University Book House.

Jauk, E., Benedek, M., Dunst, B., \& Neubauer, A. (2013). The relationship between intelligence and creativity: new support for the threshold hypothesis using empirical breakpoint detection. Intelligence, 41(4), 212-221. https://doi.org/10.1016/j.intell.2013.03.003

Karahan, T., \& Yalcin, B. (2009). The Effects of an Emotional Intelligence Skills Training Program on The Emotional Levels of Turkish University Students. Egitim Arasrinnalari, Eurasian Journal of Educational Research, 36(2), 193-208.

Katami, N. (2010). Curricula and Methods of Teaching the Gifted and Distinguished. Dar AlMasirah for Publishing, Distribution and Printing, Amman, Jordan.

Khairallah, H. (2008). Standardization of the Frank Williams Package for Grades 3 to 6 (Unpublished Master Thesis). Arabian Gulf University, Kingdom of Bahrain.

Lori, A. (2005). A Comparative Study of the Effect of Two Models of Teaching Thinking on the Growth of Higher Cognitive Abilities among a Sample of Commercial Secondary School Students in the Kingdom of Bahrain. Journal of Educational and Psychological Sciences, 7(1), 80-103.

Newma, J. (2006). Talents for Type: A guide for helping students become better creators, decision-makers, planners, predictors, and communicators. Mansfield Center CT: Creative Learning Press.

Ritter, S., \& Mostert, N. (2017). Enhancement of creative thinking skills using cognitivebased creativity training. Journal of Cognitive Enhancement, 1(3), 243-253. https:// doi.org/10.1007/s41465-016-0002-3

Saleh, M. (2016). The impact of a training program based on the emotional, cognitive interaction model on improving the communication skills of gifted students in King Abdullah II Schools of Excellence (Unpublished Master Thesis). Al-Balqa Applied University, Jordan.

Sayed E., \& Mohamed A. (2013). Gender differences in divergent thinking: the use of the test of creative thinking-drawing production on an Egyptian sample. Creativity Research Journal, 25(2), 222-227. https:// doi.org/10.1080/10400419.2013.783760

Talafha, F., \& Al-Hamran, M. (2013). The impact of teaching an educational unit according to the model of emotional, cognitive interaction on the development of perceived self-efficacy among the tenth- grade students. Journal of An-Najah University, 27(6), 1233-1266.

Talafha, F. (2009). The Effect of Using Unlimited Talents Program and Emotional Cognitive Interaction Model in Teaching Geography on the Creative Abilities and Perceptual SelfEfficiency of Tenth Grade Students (Unpublished Doctoral dissertation). Yarmouk University.

Vally, Z., Salloum, L., Al Qadera, D., El Shazly, S., Albloshi, M., Alsheraifi, S., \& Alkaabi, A. (2019). Examining the effects of creativity training on creative production, creative self-efficacy, and neuro-executive functioning. Thinking Skills and Creativity, 31(1), 70-78. https://doi.org/10.1016/j.tsc.2018.11.003

Wang, L., \& Chen, M. (2012). The Effects of Cognitive-Affective Interaction Strategy on Novices' Creative Performance in Game Design Project. Paper Presented at the 2012 IEEE 12th International Conference on Advanced Learning Technologies. https:// doi.org/10.1109/icalt.2012.27

Williams, F. (1993b). The Creativity Assessment Packet, Chesterfield MO Psychologists and Educator Inc. 